Genetics and Molecular Biology, 31, 1 (suppl), 372-376 (2008)

Copyright (C) 2008, Sociedade Brasileira de Genética. Printed in Brazil

www.sbg.org.br

Short Communication

\title{
Can Lutjanus purpureus (South red snapper) be "legally" considered a red snapper (Lutjanus campechanus)?
}

\author{
Grazielle Gomes ${ }^{1}$, Horacio Schneider ${ }^{1}$, Marcelo Vallinoto ${ }^{1}$, Simoni Santos ${ }^{1}$, Guillermo Orti ${ }^{2}$ \\ and Iracilda Sampaio ${ }^{1}$ \\ ${ }^{1}$ Laboratório de Genética e Biologia Molecular, Universidade Federal do Pará, Aldeia Bragança, \\ PA, Brazil. \\ ${ }^{2}$ Department of Biology, University of Nebraska, Lincoln, USA.
}

\begin{abstract}
Red snappers (Lutjanus purpureus in Brazil and Lutjanus campechanus in USA and Gulf of Mexico) are both under clear effect of overfishing. Because of their high morphological similarity it has already been suggested that they could possibly be considered as a single species. To investigate the degree of similarity and the genetic structure of red snapper populations we constructed a common dataset of partial D-loop mtDNA sequences of $L$. purpureus from Brazil (Amapá, Pará and Maranhão) and L. campechanus from the Atlantic coast of the USA (Florida, Louisiana and Mississippi). Phylogenetic and population genetic analyses surprisingly depicted high similarity between $L$. campechanus and $L$. purpureus, compatible with the hypothesis of a single species of red snapper for the Western Atlantic Ocean. These preliminary but very curious findings open an important discussion regarding the legislation involved on the capture of this overexploited fish resources as well as regarding their taxonomy.
\end{abstract}

Key words: red snapper, Lutjanus purpureus, Lutjanus campechanus, population genetic structure, mitochondrial D-loop.

Received: October 23, 2006; Accepted: July 10, 2007.

Lutjanus campechanus (northern red snapper) and Lutjanus purpureus (southern red snapper) are very important fish resources which are heavily fished along their distribution areas in the Western Atlantic Ocean (Rivas, 1966; Cervigón, 1993). L. campechanus populations are spread on the East Coast of the USA, from North Carolina to Florida including the entire Gulf of Mexico (Rivas, 1966). According to Rivas (1966) and Carpenter and Nelson (1971), L. purpureus is found in the Caribbean Sea, in some areas of the USA coast, and also can be found on the northern and northeastern coast of Brazil. Cervigón (1993) reports a distribution of $L$. purpureus from south of the Antilles to Northeastern Brazil.

The Brazilian Ministry for Environment has registered for the year of 1975 an amount of capture of $L$. purpureus in Brazil close to nine thousand tons. Despite improvement in fleet and fishery techniques, the production decreased seven years later to only six thousand tons, which was an indication of overfishing of southern red snappers. A more dramatic scenario has been described in USA for the northern red snapper, L. campechanus during

Send correspondence to Iracilda Sampaio. Laboratório de Genética e Biologia Molecular, Universidade Federal do Pará, Alameda Leandro Ribeiro sn, 68600-000 Bragança, PA, Brazil. E-mail: ira@ufpa.br. the last decades. In 1996 the Gulf of Mexico Fishery Management Council and the US Department of Commerce declared that $L$. campechanus was grossly overfished and called for strict management measures to restore stocks to sustainable levels (Garber et al.; 2004; Marko et al.; 2004)

There is a remarkable similarity in morphology between L. campechanus and L. purpureus, starting by their same red color pattern, and coupled with completely identical (hard and soft dorsal and anal fin rays) or overlapping (hard and soft pectoral fin rays, scale on lateral line, and gill rakers) meristic characters. Based on these characters, Cervigón (1993) raised the hypothesis of the existence of a single species of red snapper for the western Atlantic Ocean.

A recent phylogenetic analysis based on mitochondrial DNA sequences (Marko et al. 2004) surprisingly revealed that $77 \%$ of the fish sold in the marketplace in USA labeled as red snapper (Lutjanus campechanus) belonged indeed to other species of the Lutjanidae family, such as Lutjanus erythropterus, L. synagris and Rhomboplites aurorubens. According to US FDA (Food and Drug Administration) (see Marko et al., 2004) only L. campechanus can be legally labeled in USA as red snapper, regardless of the additional species called as red snappers in different countries, which is the case for L. purpureus in Brazil. However, if the hypothesis of Cervigón (1993) that $L$. 
campechanus and L. purpureus are not different species became confirmed, all issues related to stock management of red snappers must be reconsidered.

To make a contribution to this interesting debate, we carried out the first molecular comparative analysis between these two red snappers. For this purpose we collected DNA sequences of about $400 \mathrm{bp}$ for the mitochondrial control region (D-loop) from 93 specimens of L. purpureus captured in three distinct localities of northern coastal waters of Brazil (Amapá- $3^{\circ} 20^{\prime} \mathrm{N}, 50^{\circ} 41^{\prime} \mathrm{W}$; Pará- $0^{\circ} 08^{\prime} \mathrm{N}$, $47^{\circ} 32^{\prime}$ ' W and Maranhão- $\left.2^{\circ} 13^{\prime} \mathrm{S}, 42^{\circ} 39^{\prime} \mathrm{W}\right)$. These sequences were pooled together in the same alignment with D-loop sequences for $27 \mathrm{~L}$. campechanus deposited in GenBank (Garber, 2001) for Florida (AF356750AF356757), Louisiana (AF356758-AF356763) and Mississippi (AF356764-AF356776).

To extract DNA, muscle tissue was for $1 \mathrm{~h}$ by ribonuclease at $37{ }^{\circ} \mathrm{C}$, followed by $2-4 \mathrm{~h}$ incubation at $55^{\circ} \mathrm{C}$ with proteinase $\mathrm{K}$. Total DNA was then purified by standard phenol/chloroform extraction followed by precipitation using isopropanol (Sambrook et al., 1989). For each DNA sample the entire D-loop was amplified using the primers L1-5'-CCTAACTCCCAAAGCTAGGTATTC-3' and H2-5'-CCGGCAGCTCTTAGCTTTAACTA-3' designed for this work, and a fragment of approximately 400 base pairs was sequenced. PCR reactions were performed in $25 \mu \mathrm{L}$ of reaction mixture containing $4 \mu \mathrm{L}$ of $1.25 \mathrm{mM}$ $\mathrm{dNTP}, 2.5 \mu \mathrm{L}$ of buffer (10X conc.), $1 \mu \mathrm{L}$ of $25 \mathrm{mM}$ $\mathrm{MgCl} 2,0.5 \mu \mathrm{L}$ of each primer $(200 \mathrm{ng} / \mu \mathrm{L}), 1 \mu \mathrm{L}$ of total DNA $(200 \mathrm{ng} / \mu \mathrm{L}), 0.5 \mu \mathrm{L}$ of $5 \mathrm{U} / \mu \mathrm{L}$ Taq DNA polymerase and $15 \mu \mathrm{L}$ of pure water to complete the final volume of $25 \mu \mathrm{L}$. Amplifications were performed in a thermocycler with a cycling profile of $94^{\circ} \mathrm{C}$ for $3 \mathrm{~min}$ followed by $30 \mathrm{cy}$ cles of $94{ }^{\circ} \mathrm{C}$ for $30 \mathrm{~s}, 57^{\circ} \mathrm{C}$ for $1 \mathrm{~min}, 72^{\circ} \mathrm{C}$ for $2 \mathrm{~min}$, ending with an extension step at $72^{\circ} \mathrm{C}$ for $7 \mathrm{~min}$. Amplification products were purified using ExoSap IT (Amersham-Pharmacia Biotech. Inc., Piscataway, NJ, USA) and submitted to a cycle-sequencing reaction using the fluorescencelabeled dideoxy terminators supplied in the ABI PrismTM Dye Terminator Cycle Sequencing Ready Reaction kit (Applied Biosystems, Foster City, CA, USA). Sequencing reactions were performed in a $10 \mu \mathrm{L}$ reaction mixture containing $1 \mu \mathrm{L}$ of DNA, $0.5(1 \mathrm{mM})$ of primer, $1 \mu \mathrm{L}$ of Big Dye mix, $2 \mu \mathrm{L}$ of buffer (200 mM Tris/5 mM MgCl2) and $5.5 \mu \mathrm{L}$ of pure water. We used a cycling profile of 25 cycles of $96{ }^{\circ} \mathrm{C}$ for $30 \mathrm{~s}, 50{ }^{\circ} \mathrm{C}$ for $15 \mathrm{~s}$ and $60{ }^{\circ} \mathrm{C}$ for $3 \mathrm{~min}$. The products were separated by electrophoresis ( $3 \mathrm{~h}$ at $3.000 \mathrm{~V}$ ) and the sequences collected using the ABI Prism 377 automated sequencer. Sequences were aligned using the Clustal $\mathrm{X}$ version 1.8 program (Thompson et al., 1997) with default parameters. Minor modifications were made using the BIOEDIT sequence editor (Hall, 1999). Sequences of Lutjanus synagris (Lane Snapper) from Pará State (Brazil) were used as outgroup. All newly generated D-loop se- quences were deposited in GenBank (accession numbers EF656482-EF656576).

The best fit model selected by hierarchical Likelihood Ratio Test in Modeltest Version 3.6 (Posada and Crandal, 1998) was $\mathrm{HKY}+\mathrm{I}+\mathrm{G}$ with a proportion of invariant loci equal to 0.3934 and rates modeled by a gamma distribution with parameter alpha equal to 0.701 . A Neighbor Joining tree was built in PAUP* (Swofford, 2002) using the parameters chosen by Modeltest, and 1000 bootstrap pseudoreplicates were generated in order to establish node reliability. The analysis of molecular variance (AMOVA) was used to partition genetic variance within and between populations of northern and southern red snapper using Arlequin 3.0 (Excoffier et al., 2005). The exact test of sample differentiation based on haplotype frequencies (Raymond and Rousset. 1995) was accomplished using Arlequin 3.0 (Excoffier et al., 2005).

The pairwise mismatch distribution for the entire populations was generated using Arlequin 3.0 (Excoffier $e t$ al., 2005), and demographic parameters $\theta_{0}$ and $\theta_{1}$ (and their associated SSD $P$ values) were estimated using a parametric bootstrap (Rogers and Harpending, 1992; Rogers, 1995). Harpending's (1994) raggedness index was computed for mismatch distribution, and its significance tested with 1000 replicates of bootstrap in Arlequin 3.0 (Excoffier et al., 2005). Snn statistic developed by Hudson (2000) and implemented in DnaSP 4.1 (Rozas et al., 2003) was applied to evaluate the proportion of nearest-neighbor haplotypes in the area shared by both species. We also used the statistics $D$ (Tajima (1989) and $F_{S}(\mathrm{Fu}, 1997)$ implemented in the Arlequin 3.0 and in DnaSP 4.1 to infer deviations from neutrality of L. purpureus and L. campechanus populations.

Ninety-three L. purpureus from northern coastal waters of Brazil (37 from Amapá, 30 from Pará and 26 from Maranhão) were compared with 27 L. campechanus previously studied by Garber (2001). Two sequences of Lutjanus synagris from Pará were used as outgroup in the phylogenetic analysis. A total of 143 variant sites were found of which 99 were informative for parsimony ( 82 with two and 15 with three variants) and 43 were singletons. A total of 89 haplotypes were observed of which 35 were from Amapá, 29 from Pará and 25 from Maranhão populations. The highest number of absolute differences among haplotypes was 24 , and the total haplotype diversity was 0.997 . The USA populations showed the highest levels of haplotype diversity (1.0), probably as a consequence of the small sample sizes. Nucleotide diversity levels ranged from 0.014 in Louisiana to 0.027 in Pará and Maranhão populations (Table 1). North and South Atlantic populations have high haplotype and nucleotide diversities, which according to Grant and Bowen (1998) is suggestive of stable populations with long evolutionary history or secondary contact between differentiated lineages.

Both Tajima's $D$ and Fu's Fs tests were implemented to test deviations from neutrality, however, demographic 
Table 1 - Measures of mitochondrial DNA haplotype $(h)$ and nucleotide $(\pi)$ diversity, and neutrality tests observed based on the D-loop region of red snappers from six localities of the Western Atlantic.

\begin{tabular}{lrrcccc}
\hline Localities & $\mathrm{N}$ & $\mathrm{H}$ & $\mathrm{h} \pm \mathrm{sd}$ & $\pi \pm s d$ & $D$ Tajima & $F s \mathrm{Fu}$ \\
\hline Mississippi (Garber, 2001) & 13 & 13 & $1.000 \pm 0.063$ & $0.019 \pm 0.039$ & $-1.605^{\mathrm{ns}}$ & $-7.329^{* *}$ \\
Louisiana (Garber, 2001) & 6 & 6 & $1.000 \pm 0.096$ & $0.014 \pm 0.014$ & $-1.124^{\mathrm{ns}}$ & $-1.897^{\mathrm{ns}}$ \\
Florida (Garber, 2001) & 8 & 8 & $1.000 \pm 0.063$ & $0.023 \pm 0.034$ & $-1.296^{\mathrm{ns}}$ & $-2.394^{*}$ \\
North Atlantic (USA) & 27 & 26 & $0.997 \pm 0.011$ & $0.018 \pm 0.002$ & $-1.912^{*}$ & $-21.55^{* *}$ \\
Amapá & 37 & 35 & $0.997 \pm 0.007$ & $0.025 \pm 0.001$ & $-1.486^{\mathrm{ns}}$ & $-24.60^{* *}$ \\
Pará & 30 & 29 & $0.998 \pm 0.009$ & $0.027 \pm 0.001$ & $-1.083^{\mathrm{ns}}$ & $-20.10^{* *}$ \\
Maranhão & 26 & 25 & $0.997 \pm 0.012$ & $0.027 \pm 0.002$ & $-1.442^{\mathrm{ns}}$ & $-15.19^{* *}$ \\
South Atlantic (Brazil) & 93 & 83 & $0.997 \pm 0.010$ & $0.026 \pm 0.001$ & $-1.677^{\mathrm{ns}}$ & $-99.00^{* *}$ \\
All & 120 & 105 & $0.997 \pm 0.002$ & $0.025 \pm 0.001$ & $-1.862^{*}$ & $-34.26^{* *}$ \\
\hline
\end{tabular}

$\mathrm{N}=$ sample size; $\mathrm{H}=$ number of haplotypes; $h$ = haplotype diversity; $\pi=$ nucleotide diversity; $\mathrm{sd}=$ standard deviation; ns = no significant $D=$ Tajima statistic (Tajima, 1989); Fs = Fu statistic (Fu, 1997).

${ }^{*} \mathrm{p}<5 \% ;{ }^{* *} \mathrm{p}<1 \%$.

interpretations are also valid in situations where selective neutrality cannot be discounted, such as in the mitochondrial control region (Rand, 1996; Hartl and Clark, 1997). Tajima's $D$ was negative and significant only for North Atlantic populations as a whole, but not for individual populations. On the other hand, Tajima's D was negative but not significant for the three South Atlantic populations. As it is well known the expected value of Tajima's $D$ statistic is equal to zero under the null hypothesis and negative values reflect an excess of low-frequency variants in the population, consistent with positive selection or expansion (Tajima, 1989; Fu and Li, 1993). However, Fu's Fs statistic test of neutrality tends be negative when there is an excess of recent mutations (population growth) as seems to be the case in the present study for all populations, except for the small sample $(\mathrm{N}=6)$ of Louisiana. The apparent conflict between $D$ and $F S$ statistics could be due different sensitivity of these tests to sample size effect.

The phylogenetic tree showed no evidence of separation between L. campechanus and L. purpureus (Figure 1), showing an unresolved polytomy. AMOVA also shows that North and South Atlantic red snappers are not significantly different $\left(F / \Phi_{\mathrm{CT}}=0.1379\right.$, ns $)$, with almost $90 \%$ of the variance being found within populations (significant $F / \Phi_{\text {ST }}$ value of 0.1311 ) (Table 2). The exact test of sample differentiation based on haplotype frequencies (Raymond and Rousset, 1995) also showed no genetic differentiation between populations, and similar conclusions were reached based on the very sensitive Snn test (Hudson. 2000), which showed a value of 0.297 when all sub-samples of $L$. campechanus and L. purpureus were compared. Interestingly, mismatch distribution built for the entire group of Lutjanus showed a unimodal pattern (Figure 2) which is usually interpreted as representing populations that have passed through recent demographic expansion (Slatkin and Hudson, 1991; Rogers and Harpening, 1992) or through a

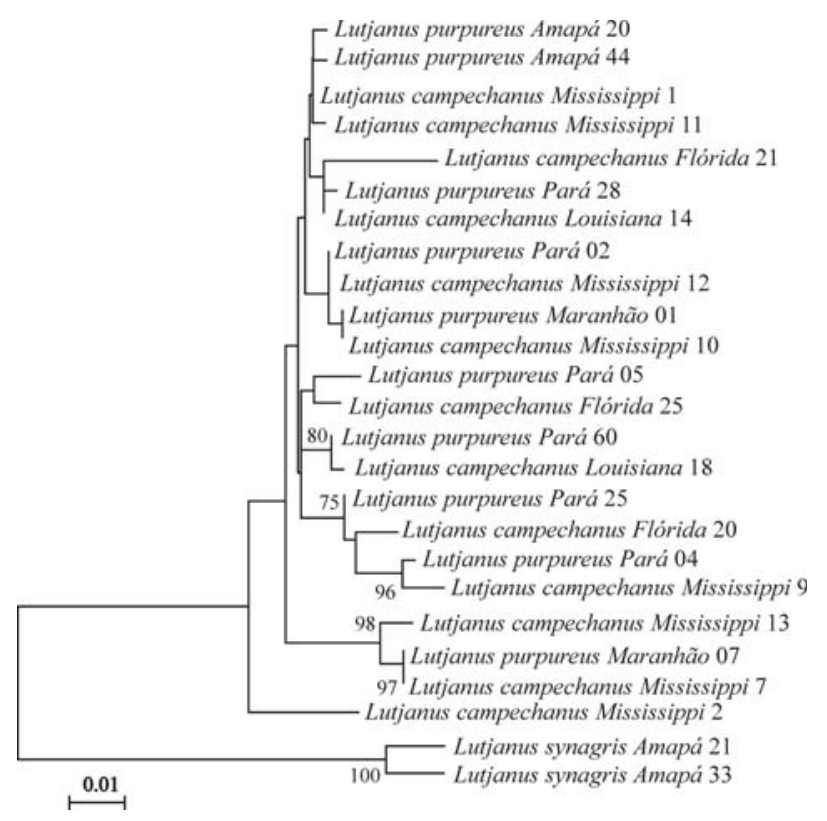

Figure 1 - Neighbor joining tree of L. purpureus and L. campechanus populations from the West Atlantic based on the control region of mitochondrial DNA. Numbers in the branches are bootstrap values obtained with 1000 pseudoreplicates. Bootstrap values shown in the tree are $=75 \%$. The numbers beside each location are the registration of the sample in the laboratory.

range expansion with high levels of migration between neighboring demes (Ray et al. 2003, Excoffier 2004). Considering these results, the hypothesis of a single species of red snappers cannot be rejected.

As morphological and the present mitochondrial data are not able to discriminate between the two Atlantic red snappers species, the most plausible and parsimonious hypothesis would be that Lutjanus from the North and South Atlantic Ocean represent slightly different populations of a single species with a large geographical distribution. This would be in agreement with the suggestion of Cervigón 
Table 2 - Analysis of Molecular Variance (AMOVA) for populations of L. campechanus and L. purpureus from six localities based on mitochondrial D-loop sequences.

\begin{tabular}{lrcccc}
\hline Source of variation & Df & Variance components & Percentage of variation & F/ $\Phi$ statistic & $p$ \\
\hline North x South populations & & & & & \\
$\quad$ Among groups & 1 & $0.81019 \mathrm{Va}$ & 13.79 & $F / \Phi_{\mathrm{CT}}=0.1379$ & $\mathrm{NS}$ \\
Among populations & 4 & $-0.04006 \mathrm{Vb}$ & -0.68 & $F / \Phi_{\mathrm{SC}}=-0.0079$ & $\mathrm{NS}$ \\
Within populations & 114 & $5.10436 \mathrm{Vc}$ & 86.89 & $F / \Phi_{\mathrm{ST}}=0.1311$ & $<0.001$ \\
All & 119 & 5.87449 & & & \\
\hline All populations & & & & & \\
Among populations & 5 & $0.32368 \mathrm{Va}$ & 5.96 & & \\
Within populations & 114 & $5.10436 \mathrm{Vb}$ & 94.04 & & \\
All & 119 & 5.42804 & & & \\
\hline
\end{tabular}

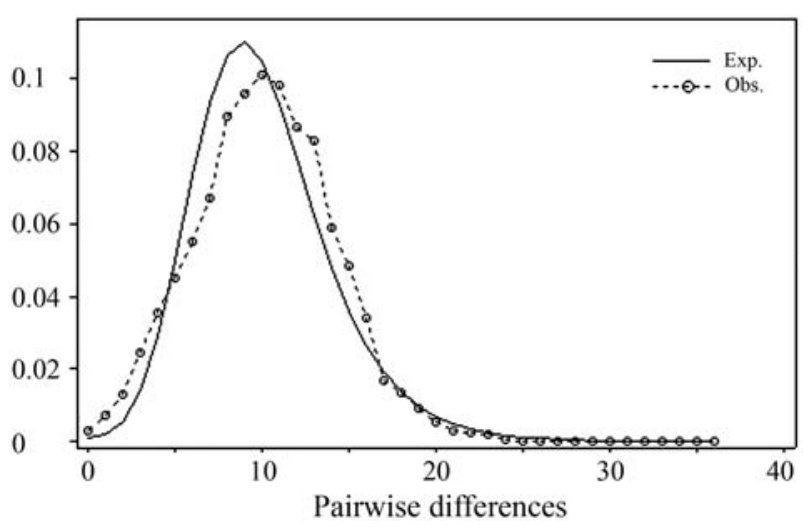

Figure 2 - Mismatch distribution based on 120 D-loop sequences of $L$. purpureus and L. campechanus from six localities of the West Atlantic. The solid line is the observed and the dotted line is the expected distribution of the pairwise differences.

(1993). However, considering the economic importance of this overexploited fish resource, and all legal questions related to stock management, as well as the mislabelling issue raised by Marko et al (2004), any decision about their taxonomic status should be well supported by additional genetic data, including the analysis of more populations along the entire distribution range of $L$. purpureus/campechanus, as well as additional representatives of the Lutjanidae family.

\section{Acknowledgments}

This study was funded by CNPq-PADCT/MCT (Millenium Project, grant no. 62.0052/01-5).

\section{References}

Carpenter JS and Nelson WR (1971) Fishery potential for snapper and grouper in the Caribbean area and the Guianas. FAO Fish Rep Rome 7:21-26.

Cervigón F (1993) Los Peces Marinhos de Venezuela, v. II. $2^{\text {nd }}$ ed. Fundacion Científica Los Roques, Caracas, 498 pp.

Excoffier L (2004) Patterns of DNA sequence diversity and genetic structure after a range expansion: Lessons from the infinite-island model. Mol Ecol 13:853-864.
Excoffier L, Laval G and Schneider S (2005) Arlequin (v. 3.0): An integrated software package for population genetics data analysis. Evol Bioinform Online 2005:47-50 (http://systbio.org/?q = node/73).

Fu YX (1997) Statistical methods of neutrality of mutations against population growth, hitchhiking and background selection. Genetics 147:915-925.

Fu YX and Li WH (1993) Statistical tests of neutrality of mutations. Genetics 133:93-709.

Garber AF (2001) Utilization of a hypervariable region as a molecular marker for red snapper, Lutjanus campechanus, stock enhancement. M.Sc. Thesis. University of Southern Mississippi, Hattiesburg.

Garber AF, Tringali MD and Stuck KC (2004) Population structure and variation in Red snapper (Lutjanus campechanus) from the Gulf of Mexico and Atlantic Coast of Florida as determined from mitochondrial DNA control region sequence. Mar Biotechnol 6:175-185.

Grant WS and Bowen BW (1998) Shallow population histories in deep evolutionary lineages of marine fishes: Insights from sardines and anchovies and lessons for conservation. J Hered 89:415-426.

Hall TA (1999) BioEdit: A user-friendly biological sequence alignment editor and analysis program for Windows 95/98/NT. Nucleic Acids Symp Ser 41:95-98.

Harpending HC (1994) Signature of ancient population growth in a low-resolution mitochondrial DNA mismatch distribution. Hum Biol 66:591-600.

Hartl DL and Clark AG (1997) Principles of Population Genetics. Sinauer Associates, Sunderland, 542 pp.

Hudson RR (2000) A new statistic for detecting genetic differentiation. Genetics 155:2011-2014.

Marko PB, Lee SC, Rice AM, Gramling JM, Fitzhenry TM, Mcalister JS, Harper GR and Moran AL (2004) Mislabelling of a depleted reef fish. Nature 430:309-310.

Posada D and Crandall KA (1998) MODELTEST: Testing the model of DNA substitution. Bioinformatics 14:817-818.

Rand DM (1996) Neutrality tests of molecular markers and the connections between DNA polymorphism, demography, and conservation biology. Conserv Biol 10:665-671.

Ray N, Currat M and Excoffier L (2003) Intra-Deme molecular diversity in spatially expanding populations. Mol Biol Evol 20:76-86. 
Raymond M and Rousset F (1995) An exact test for population differentiation. Evolution 49:1280-1283.

Rivas LR (1966) Review of the Lutjanus campechanus complex of red snappers. Q J Flor Acad Sci 29:117-136.

Rogers AR (1995) Genetic evidence for a Pleistocene population explosion. Evolution 49:608-615.

Rogers AR and Harpending HC (1992) Population growth makes waves in the distribution of pairwise genetic differences. Mol Biol Evol 9:552-569.

Rozas J, Sánchez-DelBarrio JC, Messeguer X and Rozas R (2003) DNASP, DNA polymorphism analyses by the coalescent and other methods. Bioinformatics 19:2496-2497.

Sambrook J, Fritsch EF and Maniatis T (1989) Molecular Cloning: A Laboratory Manual. Cold Spring Harbor Laboratory Press, Could Spring Harbor.
Slatkin M and Hudson RR (1991) Pairwise comparisons of mitochondrial DNA sequences in stable and exponentially growing populations. Genetics 129:555-562.

Swofford DL (2002) PAUP, Phylogenetic Analysis Using Parsimony (and other methods), v. 4b10. Sinauer Associates, Inc. Publisher, Sunderland.

Tajima F (1989) Statistical method for testing the neutral mutation hypothesis by DNA polymorphism. Genetics 123:585-595.

Thompson JD, Gibson TJ, Plewniak F, Jeanmougin F and Higgins DG (1997) The CLUSTALX windows interface: Flexible strategies for multiple sequence alignment aided by quality analysis tools. Nucleic Acids Res 24:4876-4882.

Associate Editor: Antonio Solé-Cava

License information: This is an open-access article distributed under the terms of the Creative Commons Attribution License, which permits unrestricted use, distribution, and reproduction in any medium, provided the original work is properly cited. 